\section{Instrumentos de Avaliação da Capacidade Mental: tentativa de salvaguardar a autonomia e dignidade do indivíduo}

Lopes. L

Programa de Pós-graduação em Bioética da Universidade de Brasília. E-mail: $\underline{\text { liarlopes@hotmail.com }}$

\section{Albuquerque, A}

Programa de Pós-graduação em Bioética da Universidade de Brasília

PALAVRAS-CHAVE: capacidade mental, instrumentos de avaliação, autonomia, dignidade

Introdução: A história da humanidade sempre foi pontuada por grandes questões com as diferenças entre os indivíduos. $\mathrm{Na}$ gênese dos povos, sempre houve a necessidade de segregação e de hierarquização entre os indivíduos, no intuito, em grande parte das vezes, de reserva de poder. Para tanto, valeu-se muito de diferenças entre os indivíduos, de diversas naturezas, intrínsecas ou extrínsecas, mínimas ou não, adaptativas ou nem tanto, incorrendo então em inúmeras atrocidades no desenvolvimento das sociedades, ferindo direitos, até mesmo atualmente, onde os Direitos Humanos são amplamente estabelecidos. Boa parte dos afetados no desenvolvimento das sociedades, inclusive hoje, constitui-se de pessoas com alguma vulnerabilidade que interfere na capacidade mental: enfermos, crianças, idosos, vulnerados, entre outros. Em grande parte, tais alterações são perfeitamente compatíveis com a vida plena, apesar de trazer particularidades e certa vulnerabilidade ao sujeito acometido, quer diretamente, quer indiretamente. Contudo, precisamos, especialmente no dia-a-dia dos cuidados de saúde e na vida jurídica, garantia dos direitos, também como agilidade, segurança e replicabilidade na avaliação da capacidade mental dos indivíduos. Métodos: Revisão de literatura científica. Resultados: Encontramos alguns instrumentos que preenchem os critérios se agilidade, segurança e replicabilidade na avaliação da capacidade mental na prática clínica de saúde e na vida jurídica, em especial, uma ferramenta chamada McCAT-CR. Conclusão: Vemos, sobretudo do ponto de vista ético, a importância da determinação da capacidade mental e seus desdobramentos individuais e sociais. Entretanto, notamos uma ausência de esforços mais aprimorados, no âmbito nacional e internacional, no intuito de discutir o instituto da capacidade mental, com a finalidade de melhor conceituação, terminologia e aplicabilidade do mesmo, visando a garantir direitos individuais e coletivos, sobretudo alicerçados nos Direitos Humanos. Acreditamos que se faz imprescindível agenda ética comprometida com a criação de forças-tarefas com a finalidade de discutir e reformular constantemente o instituto da capacidade mental perante modificações sociais continuadas e adventos da renovação dos conhecimentos. Assim, sugerimos, no Brasil, especialmente no nosso meio, a criação de um instrumento que garanta agilidade, replicabilidade e segurança na avaliação da capacidade mental dos indivíduos, especialmente, os em estado de vulnerabilidade, garantindo os princípios de autonomia e dignidade humana, essencialmente.

\section{REFERÊNCIAS}

[1] Foucault M. A História da Loucura. Perspectiva. 1978.

[2] Organização Mundial de Saúde. Livro de Recursos da OMS sobre Saúde Mental, Direitos Humanos e Legislação. 2005

www.who.int/mental_health/policy/Livroderecursosrevi sao_FINAL.pdf

[3] Purser K. Capacity, Assessment and Law. Springer. 2017

[4] LEI $\mathrm{N}^{\circ}$ 13.146, DE 6 DE JULHO DE 2015. http://www.planalto.gov.br/ccivil_03/_ato20152018/2015/lei/113146.htm

[5] Taborda J, Abdalla-Filho E, de Moraes T, Mecler K. Avaliação da capacidade civil. In: Taborda J, Abdalla Filho E, Chalub M, editores. Psiquiatria forense. $2^{\mathrm{a}}$ ed. Porto Alegre: Artmed; 2012. p. 205-19. 19. 